\title{
Population structure of daytime surface swarms of the euphausiid Meganyctiphanes norvegica in the Bay of Fundy
}

\author{
Stephen Nicol \\ Department of Biology, Dalhousie University, Halifax, Nova Scotia B3H 4J1, Canada
}

\begin{abstract}
Daytime surface swarms of the euphausiid Meganyctiphanes norvegica occurring off Brier and Long Islands in the Bay of Fundy were studied during the summers of 1979 to 1983. Individual swarms were found to have highly skewed sex ratios; both male dominated and female dominated swarms were encountered but female swarms were more common. Individuals in surface swarms comprised a restricted part of the population when compared to samples taken at depth and when compared to the population structure of this species at similar times of year in other studies. Both males and females were in breeding condition; males possessed ripe spermatophores, females were fertilized and exhibited ovaries in an advanced stage of maturation. The presence of swarms was accompanied by bursts of $M$. norvegica eggs in the plankton on spatial and temporal scales coincident with the swarming events. It is concluded that these swarms are related to reproductive activity.
\end{abstract}

\section{INTRODUCTION}

The presence of dense daytime aggregations of euphausiids at the water surface is a spectacular event characterised by a patchy reddening of the water and usually accompanied by an abundance of aerial and aquatic predators feeding on this locally abundant food supply. Because of their conspicuousness, surface swarms have regularly been reported, but have seldom been studied; 3 factors are responsible for this. Firstly, most species of euphausiids are found in water deeper than $100 \mathrm{~m}$ and therefore their centres of abundance are offshore. Secondly, swarming generally occurs on a small scale - less than 5 ha. Thirdly, swarming events occur sporadically with no known periodicities. These 3 factors combine to reduce the chances of surface swarming being observed and to thwart any attempts at direct study. Many species of euphausiids live in dense aggregations in the oceans and make diurnal vertical migrations. According to most observations, however, the population should reach its maximum depth during daylight hours. Mauchline (1980) lists 31 of the 85 species of euphausiids known to occur in dense aggregations; of these 18 are reported to occur in surface swarms. All surface swarming species have normal daytime depths of less than $600 \mathrm{~m}$ and all migrate vertically to the surface at night (Mauchline, 1980).

Only 4 studies have specifically addressed the nature of surface swarming in euphausiids other than Euphausia superba (which may be a special case since it appears to spend much of its life in the surface layers). Zelickman (1961) examined and described surface swarms of Thysanoessa inermis and Thysanoessa raschii in the Barents Sea, Komaki (1967) and Endo (1981) both worked on the fishery for Euphausia pacifica off the Japanese coast, and Brown et al. (1979) investigated surface swarms of Meganyctiphanes norvegica in the Bay of Fundy. Most often, however, daytime surface swarms are reported as a result of their being encountered accidentally; thus a record of their occurrence is dependent on the presence of an interested party during a surface swarming event.

Komaki (1967) outlined 4 hypotheses which have been proposed to account for daytime surface swarming in euphausiids. Firstly, euphausiids congregate at the surface to feed. Secondly, they are brought to the surface passively by physical processes or that they are feeding on organisms which have themselves been advected to the surface. Thirdly, they are driven to the surface by predators from below. Fourthly, they actively seek the surface for some process related to 
reproduction. Most of the published reports of surface swarming by euphausiids do not provide enough information to determine whether any of the hypotheses proposed are applicable. The study reported here involved the examination of a population of surface swarming euphausiids over a period of $5 \mathrm{yr}$. The aim of this study was to provide a detailed description of the animals that make up the swarms. Information on the detailed population structure of surface swarms provides a basis for the examination of this phenomenon from the point of view of the hypotheses that have been proposed to account for it.

\section{MATERIALS AND METHODS}

Daytime surface swarms of Meganyctiphanes norvegica were reported by Brown et al. (1979) to occur off Brier and Long Islands in the Bay of Fundy during Jul and Aug. This area was studied intensively during the summers of 1979-1983 in order to examine the occurrence and nature of the surface swarms. Surface swarms were found to be composed of 3 types of aggregation: shoals with densities of 1 to 100 individuals $\mathrm{m}^{-3}$, swarms with densities of 100 to 600,000 ind. $\mathrm{m}^{-3}$ and schools with swarm densities but with parallel orientation (terminology after Mauchline, 1980). The swarming area could cover several ha, and within shoal densities swarms and schools ( 1 to $3 \mathrm{~m}$ diameter) were found at irregular intervals. Schools were composed of the same animals as swarms, the difference in orientation arising because schools were moving through the water whereas swarms were stationary. Because of the homogeneity in these 2 types of aggregations, and in order to minimize terminology, high density aggregations will be termed swarms unless a point is being made about their orientation.

The primary device used to obtain samples of swarm members was a hand-held dip net (mouth diameter $0.25 \mathrm{~m}$, mesh $0.5 \mathrm{~cm}$, handle length 1.5 to $2.0 \mathrm{~m}$ ). Such nets allowed point samples to be taken of individual swarms or parts of swarms in the uppermost metre of the water column. A sub-sample ( $>100$ if possible) was preserved immediately in $10 \%$ formalin in seawater. Shoal densities were sampled either by aimed collections using dip nets or by use of towed nets. Nets were deployed from the stern of a $10 \mathrm{~m}$ fishing boat on $20 \mathrm{~m}$ of rope and were towed for $10 \mathrm{~min}$ at a speed of between 1 and $2 \mathrm{kt}$. A curved track was followed in order to minimize avoidance of the boat by the euphausiids. Four types of net were used: an Isaacs Kidd type trawl $1 \mathrm{~m}$ to a side; mesh $0.5 \mathrm{~cm}$ during 1980-1982; an unmetered $360 \mu \mathrm{m}, 3 / 4 \mathrm{~m}$ plankton net in $1979-81$; a $270 \mu \mathrm{m}, 3 / 4 \mathrm{~m}$ metered plankton net in 1982 and a $460 \mu \mathrm{m}, 1 \mathrm{~m}$ metered plankton net in 1983 . In addition to the sampling off Brier and Long Islands several comparative sampling trips were made. Samples from depth were collected on two cruises: from July 16 to 22, 1981 on Pandora II on the Scotian Shelfand from June 19 to June 29, 1982 on the CSS Dawson off South West Nova Scotia (Figure 1). Sampling gear consisted of: a $360 \mu \mathrm{m}, 1 \mathrm{~m}$ plankton net on the Pandora cruise and $1 \mathrm{~m}$ bongo nets 153 and $333 \mu \mathrm{m}$ mesh on the Dawson cruise. Two other sites of surface swarming were sampled, Passamaquoddy Bay on August 27, 1981 and a single sample dip netted from a swarm off North Sydney on August 12, 1982. A total of 107 samples were obtained from the swarms off Brier Island on 21 days when swarms were observed.

An subsample of at least 30 euphausiids (where possible) was removed from each preserved sample and examined microscopically. Each animal was identified to species level using the key provided in Einarsson (1945). The carapace length was measured by means of a vernier micrometer, from the anterior tip of the rostrum to the mid dorsal posterior edge of the carapace.

For the determination of the sex ratio, a larger subsample $(\mathrm{N}>100$ animals when possible) was removed from each preserved sample and sexed. The sex ratio was expressed as percentage female and compared to a theoretically 'normal' sex ratio of $50 \%$ female.

(i) Males. All males in each subsample were examined for the presence of spermatophores, either in the ejaculatory ducts, extruded or attached to the appendages.

(ii) Females. All females in each subsample were examined for attached spermatophores or for the presence of a sperm plug on the thelycum. The ovaries of females from selected subsamples were removed and squashed under a coverslip on a slide and examined microscopically. The ova within the ovary were measured using an ocular micrometer and classified by reference to the dominant stage of development using the scheme of Mauchline and Fisher (1969). Stage I ova had a diameter of up to $0.1 \mathrm{~mm}$ with a large nucleus and a granular cytoplasm. Stage II ova measured 0.1 to $0.2 \mathrm{~mm}$ in diameter with a large nucleus and a very granular cytoplasm. Stage III ova had a diameter of 0.2 to $0.3 \mathrm{~mm}$ with yolk globules present and a visible nucleus. Stage IV ova measured 0.3 to $0.4 \mathrm{~mm}$ in diameter and the nucleus was rarely visible through the cytoplasm which contained many yolk globules.

During the 1982 field season, plankton tows were made in the vicinity of the swarming area using a $270 \mu \mathrm{m} 3 / 4 \mathrm{~m}$ diameter net. Plankton tows sampled the top metre of the water column both on days when swarms were present and on days when they were absent. Two areas were sampled, the area where the swarms were most often seen and the area just inshore 
Fig. 1. Sampling sites. S1: Brier and Long Islands; S2: Pandora II cruise, Scotian Shelf, 21. Jul 81; S3: Passamaquoddy Bay, 27. Aug 81; S4: Dawson Cruise, S. W. Nova Scotia, 20. Jun 82; S5: North Sydney, 12. Aug 82

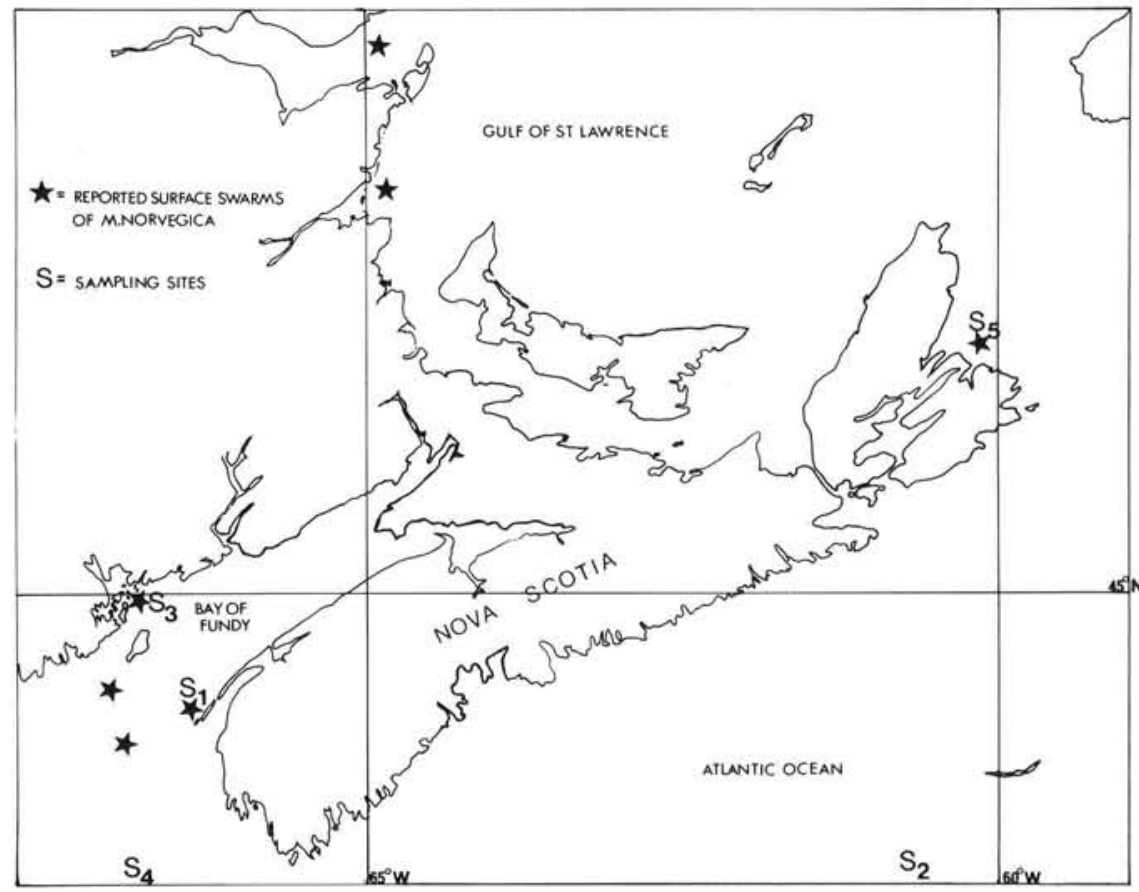

of where surface swarming was seen. All plankton tows were examined for the presence of Meganyctiphanes norvegica eggs. Each settled plankton sample of known volume was subsampled in triplicate using a wide-mouthed pipette of $0.5 \mathrm{ml}$ volume. Each subsample was examined microscopically and the total number of eggs was counted. The mean value of the triplicates was taken to represent the number of eggs per $0.5 \mathrm{ml}$ of the settled sample and this value was converted to the number of eggs $\mathrm{m}^{-3}$.

\section{RESULTS}

\section{Size of euphausiids}

All euphausiids from samples of surface swarms off Brier and Long Islands, from Passamaquoddy Bay and from North Sydney were Meganyctiphanes norvegica. The range of means from swarms for all years falls within a very narrow spread: 8.0 to $8.9 \mathrm{~mm}$ for females and 7.3 to $8.5 \mathrm{~mm}$ for males (Table 1). The range for males is contracted ( 7.6 to $8.5 \mathrm{~mm}$ ) if the small sample from 31. 7. 1982 is omitted. Mean carapace length of males and females from the Pandora cruise (21. Jul 81) differed significantly from the single day sample from swarms off Brier Island in 1981 ( $t=10.7$ for males, 5.1 for females, $P<0.01$ in both cases) (Fig. 2). Mean carapace lengths of males and females from the Dawson cruise (20. Jun 82 ) differed significantly from those for the first day that swarming was observed off Brier
Island during $1982(\mathrm{t}=2.4$ and 9.9 respectively, $\mathrm{P}<0.05$ and $<0.01$ ) (Fig. 3). Variances from average carapace length data for Dawson cruise and Pandora cruise are greater than most of those from surface swarms reflecting the wider spread of sizes present in the population at depth. The size range in the surface swarms appears to occupy a restricted portion of the size range of the 'normal' population, comprising only the larger individuals. Samples from the 3 swarming areas contain the same portion of the population. No significant changes in mean carapace lengths were detected between samples collected at the beginning of the sampling season (6. Jul 82) compared to those collected at the termination of sampling (18. Aug 82; plus 19. Aug 82 for males); (males: $t=0.825, P>0.05$, females: $t=0.209, P>0.05$ ).

There appears to be a relation between mean carapace length of males and females in a given swarm (Fig. 4). This relation may be a result of the length dependancy of the swimming speed in euphausiids (Hamner et al., 1983) leading to an assortment of the swarming population by size.

\section{Sex ratio}

Sex ratios of samples dip netted from surface swarms were highly skewed with $85 \%$ of swarms sampled demonstrating a sex ratio significantly different from a theoretically expected value of $50 \%$ female (Fig. 5). Samples taken in 1979 were male-dominated whereas 
Table 1. Meganyctiphanes norvegica. Mean carapace length for each day of sampling

\begin{tabular}{|c|c|c|c|c|c|c|}
\hline \multirow[t]{2}{*}{ Date } & \multicolumn{3}{|c|}{ Females } & \multicolumn{3}{|c|}{ Males } \\
\hline & $\mathrm{N}$ & $\overline{\mathrm{X}}$ & $\mathrm{SD}$ & $\mathrm{N}$ & $\overline{\mathrm{X}}$ & $\mathrm{SD}$ \\
\hline $9 . / 10.8 .79$ & 53 & 8.7 & 0.53 & 231 & 8.5 & 0.65 \\
\hline 26. 7.80 & 170 & 8.4 & 0.66 & 83 & 7.6 & 0.49 \\
\hline 25. 8.80 & 41 & 8.0 & 0.56 & 52 & 7.6 & 0.34 \\
\hline $21.7 .81 \mathrm{a}$ & 54 & 7.3 & 1.55 & 43 & 6.8 & $0.66^{\circ}$ \\
\hline 27. $8.81 \mathrm{~b}$ & 34 & 8.0 & 0.54 & 52 & 8.0 & 0.46 \\
\hline 28. 8.81 & 17 & 8.8 & 0.85 & 42 & 8.1 & 0.49 \\
\hline $20.6 .82 \mathrm{c}$ & 261 & 8.0 & 0.96 & 66 & 7.6 & $0.66^{\circ}$ \\
\hline 6. 7.82 & 158 & 8.8 & 0.54 & 82 & 7.9 & 0.57 \\
\hline 7. 7.82 & 37 & 8.8 & 0.72 & 34 & 8.2 & 0.69 \\
\hline 31. 7.82 & 153 & 8.7 & 0.72 & 6 & 7.3 & 1.18 \\
\hline 2. 8.82 & 569 & 8.8 & 0.55 & 13 & 7.8 & 0.28 \\
\hline 4. 8.82 & 452 & 8.8 & 0.53 & 137 & 8.0 & 0.51 \\
\hline 6. 8.82 & 443 & 8.8 & 0.56 & 132 & 8.1 & 0.50 \\
\hline 7. 8. 82 & 319 & 8.9 & 0.54 & 175 & 8.1 & 0.50 \\
\hline 12. 8. $82 \mathrm{~d}$ & 30 & 8.5 & 0.65 & - & - & - \\
\hline 17. 8. 82 & 114 & 8.6 & 0.68 & 44 & 7.9 & 0.53 \\
\hline 18. 8. 82 & 286 & 8.7 & 0.59 & 126 & 8.0 & 0.46 \\
\hline 19. 8. 82 & 30 & 8.9 & 0.45 & 9 & 8.3 & 0.31 \\
\hline \multicolumn{7}{|c|}{$\begin{array}{l}\mathrm{N}=\text { Number of individuals examined; } \overline{\mathrm{X}}=\text { mean carapace length }(\mathrm{mm}) ; \mathrm{SD}=\text { standard deviation of the mean; } \mathrm{a}=\mathrm{Pandora} \text { II } \\
\text { cruise samples; } \mathrm{b}=\text { Passamaquoddy Bay surface swarms; } \mathrm{c}=\text { Dawson cruise samples; } \mathrm{d}=\mathrm{N} \text {. Sydney surface swarm; }{ }^{*} \text { samples } \\
\text { obtained at depth }\end{array}$} \\
\hline
\end{tabular}

those from 1982 were, in all but 2 cases, female-dominated. During 1982 there were days during which samples showed more variation in the sex ratio than others: 2. Aug 82 where all 19 swarms sampled were $>90 \%$ female compared to 7 . Aug 82 when the range from 13 swarms was from 44 to $88 \%$ female. On $1 \mathrm{~d}$ only were both male and female dominated swarms found (25. Aug 80). The distribution of sex ratios from samples obtained by dip nets from shoals and those dip-netted from swarms were not significantly different $\left(\mathrm{X}^{2}=4.24,4 \mathrm{df}, \mathrm{P}>0.05\right)$. Samples obtained by means of towed nets in the swarming area, however, did differ significantly from that dip-netted from swarms $\left(\mathrm{X}^{2}=30.62,9 \mathrm{df}, \mathrm{P}<0.001\right)$. Sex ratios of samples from Passamaquoddy Bay ranged from 16 to $44 \%$ female, and the North Sydney swarm sample was

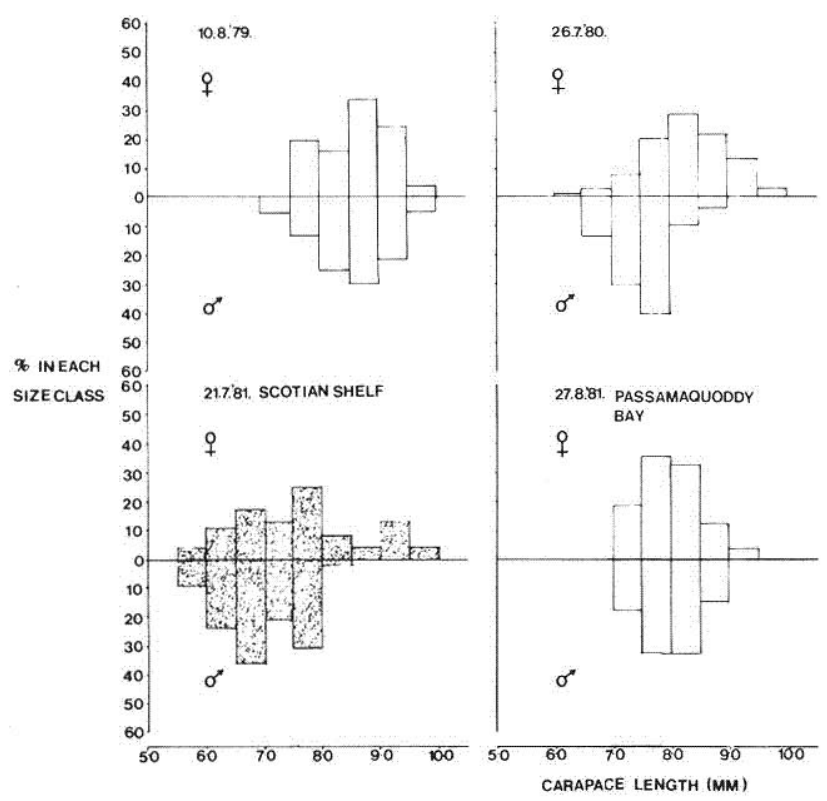

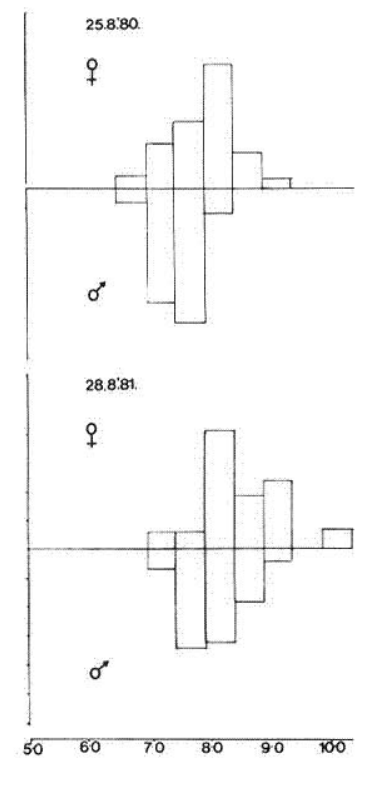

Fig. 2. Meganyctiphanes norvegica. Length frequency histograms comparing carapace lengths from each days' samples obtained from swarms off Brier and Long Islands from 1979 to 1981 with those obtained offshore at depth (shaded) and those from the Passamaquoddy Bay swarms 
Fig. 3, Meganyctiphanes norvegica. Length frequency histograms comparing carapace lengths in samples from surface swarms off Brier and Long Islands on first and last days of sampling during 1982 with those obtained from depth offshore (shaded) and the single sample from the swarm from N. Sydney. Only females were found in this sample

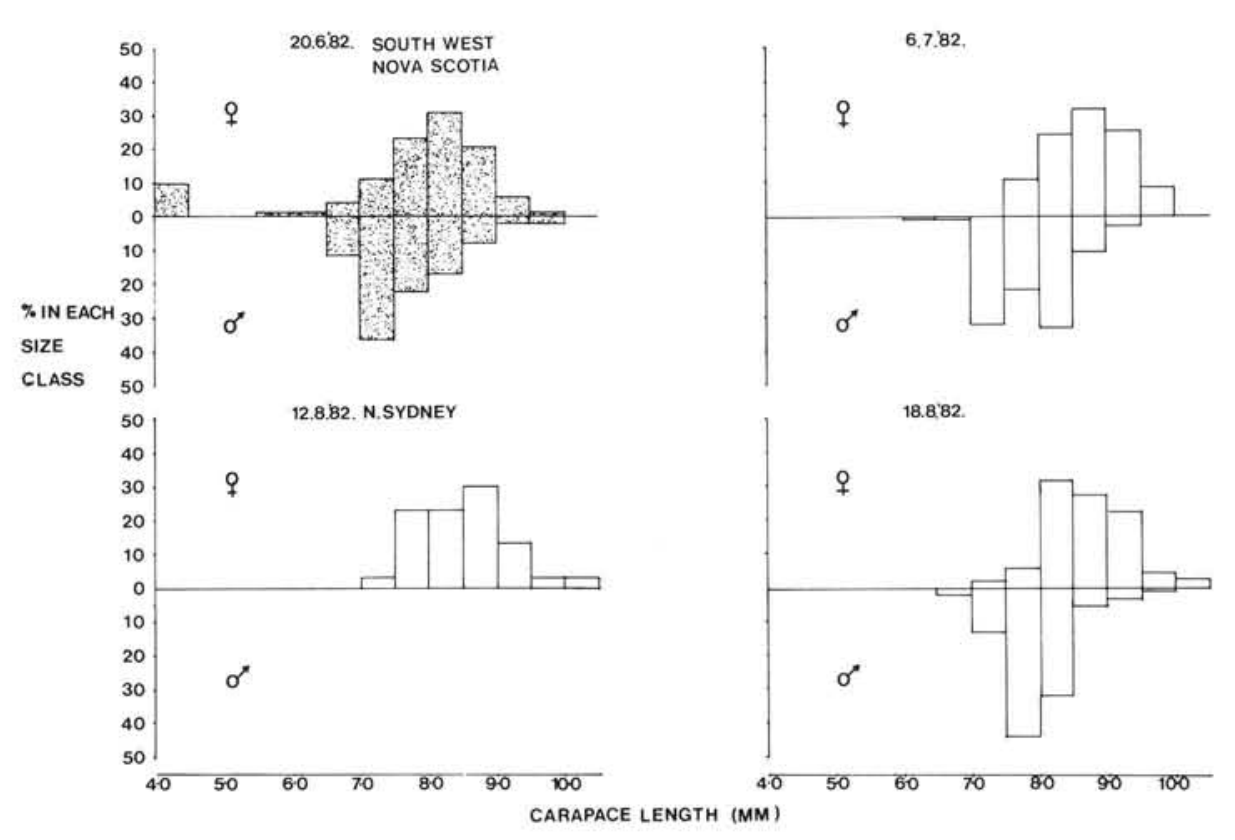

\section{Sexual characteristics}

$100 \%$ female. Samples taken at depth offshore disskewed values but the distribution was not significantly different from that for the swarms dip-netted from Brier Island $\left(\mathrm{X}^{2}=6.41,4 \mathrm{df}, \mathrm{P}>0.05\right)$.

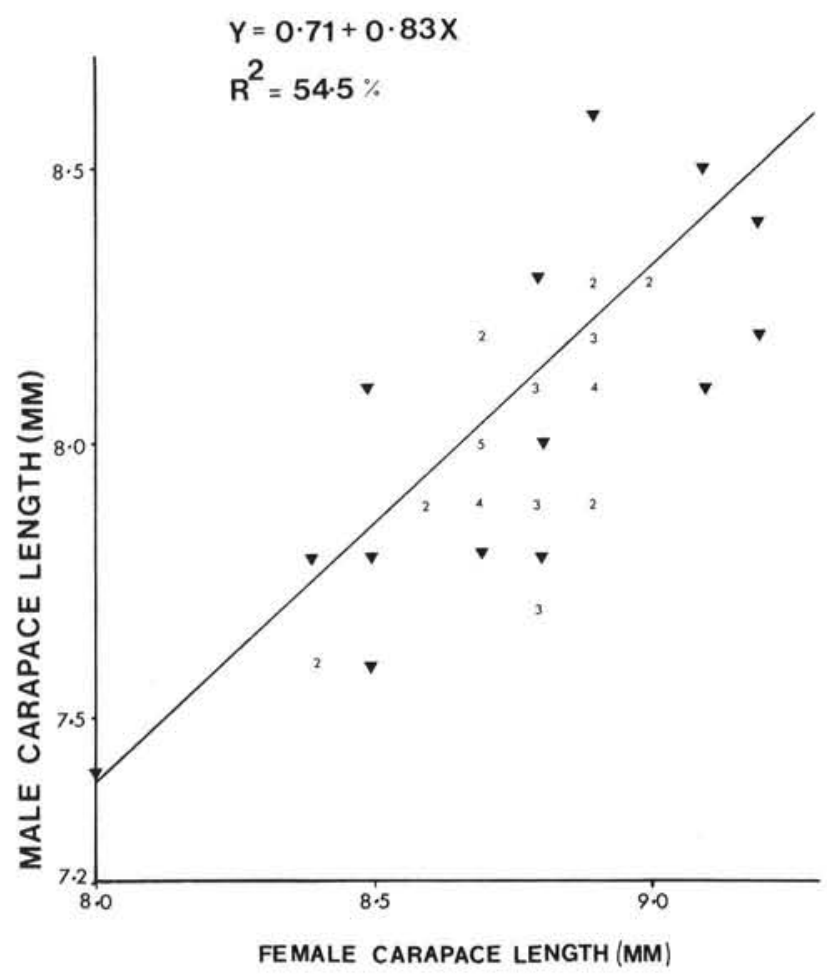

Fig. 4. Meganyctiphanes norvegica. Relation between mean carapace length of females in a swarm and mean carapace length of males in the same swarm. Numbers: multiple occurrences. Regression line fitted by method of least squares
Males. The great majority of males ( $>82 \%$ ) in each day's samples from all sampling locations were in breeding condition, as indicated by the presence of 2

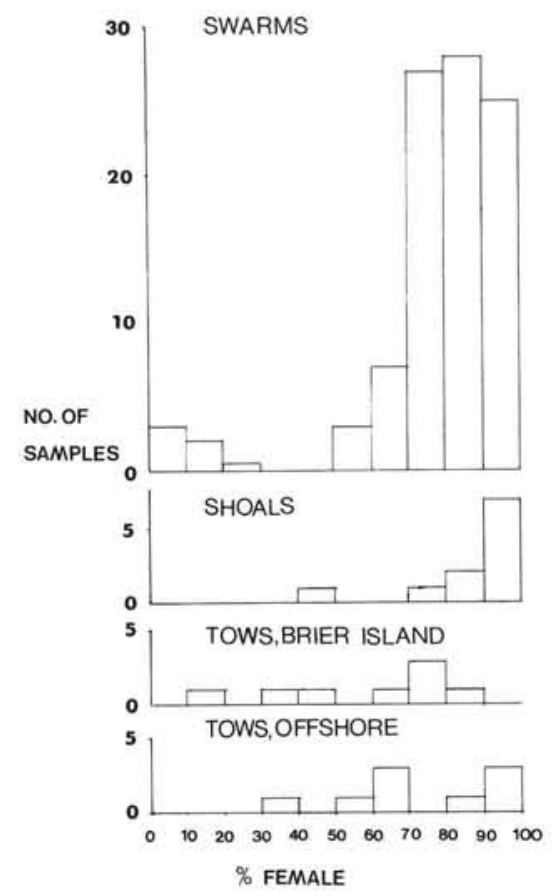

Fig. 5. Meganyctiphanes norvegica. Distribution of sex ratios in samples obtained from surface swarms and shoals off Brier and Long Islands by dip nets, compared to sex ratios in samples from the same area obtained by towed nets and in the samples obtained in plankton nets offshore (Pandora II and Dawson cruises) 
spermatophores in the ejaculatory ducts. A small percentage $(<8 \%)$ appeared to be in the process of spermatophore transfer, as indicated by the extrusion of one or more spermatophores. Another small percentage $(<11 \%)$ appeared either to have already transferred their spermatophores or not to have developed any. An examination of the 'food basket' of individuals from swarms revealed that 18 males had sper- matophores present in them; of these 10 had empty ejaculatory ducts.

Females. All but 6 mature females from all samples were fertilized. Fertilization was generally evident by the presence of a sperm plug in the thelycum though in a small number of cases $\left(<19 \% \mathrm{~d}^{-1}\right)$ spermatophores were found attached. The percentage of females with attached spermatophores was significantly higher in

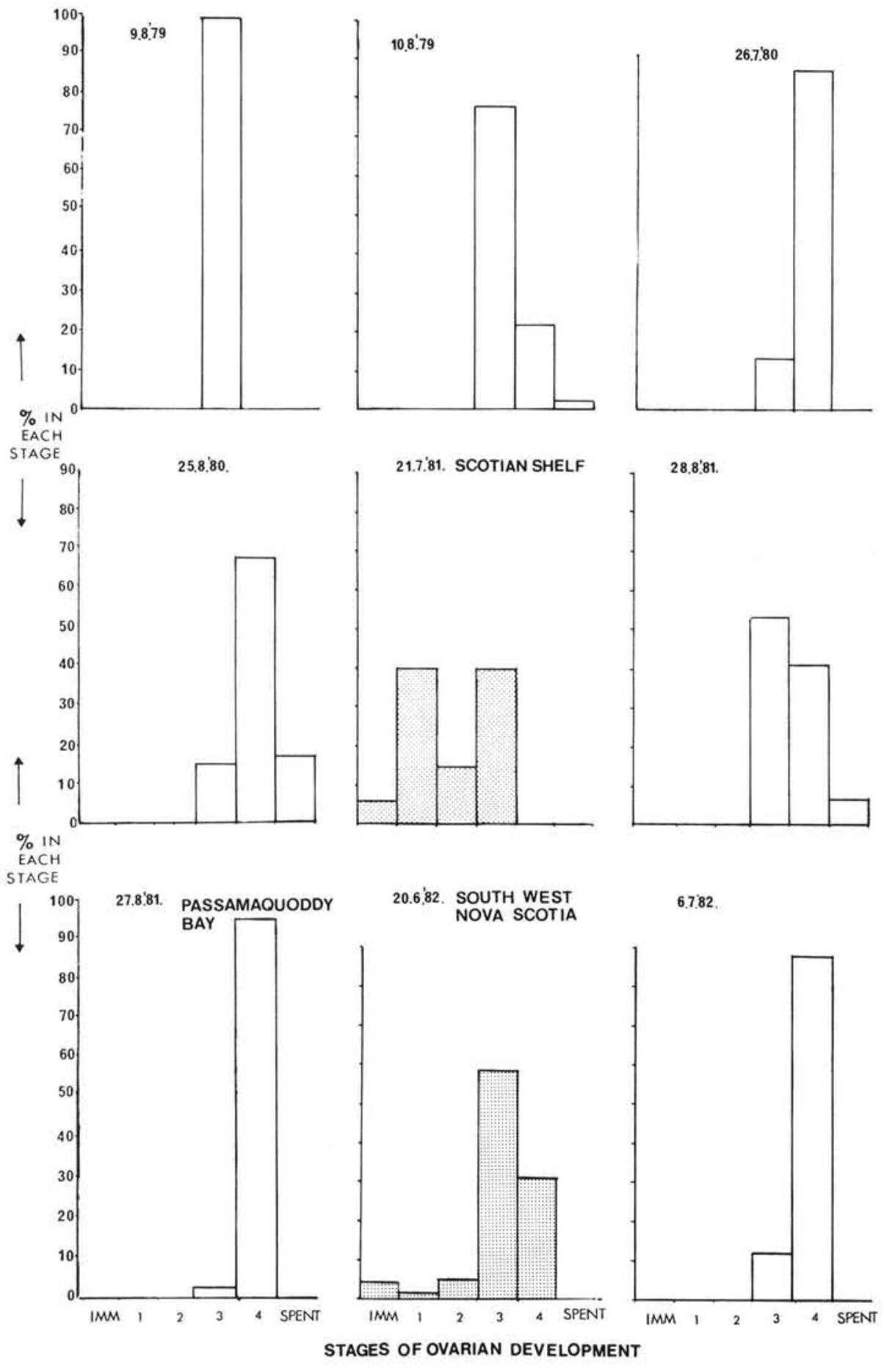

Fig. 6. Meganyctiphanes norvegica. Percentage of females with ovaries in each stage of development from all days' samples 1979-1981 and from the first 2 days' samples, 1982. Offshore samples shaded. $\mathrm{IMM}=$ immature. For description of stages, see text 
male-dominated swarms than in female-dominated swarms $\left(10 \%\right.$ vs. $\left.0.4 \%, \mathrm{X}^{2}=300,3 \mathrm{df}, \mathrm{P}<0.001\right)$. A further 9 females had spermatophores present in their 'food baskets'.

The number of females in each stage of ovarian development for selected samples is shown in Fig. 6 (samples from the other $6 \mathrm{~d}$ in 1982 only contained females with Stage 4 ovaries, so these are not represented graphically). The samples from the Pandora II cruise (21. Jul 81) had a significantly different distribution of ovarian stages from the swarms of 28 . Aug 81 $\left(\mathrm{X}^{2}=14.6,5 \mathrm{df}, \mathrm{P}<0.05\right)$ and that from the cruise off S.W. Nova Scotia (20. Jun 82 ) also was significantly different from that in swarms on 6. Jul $82\left(\mathrm{X}^{2}=127.5\right.$, $5 \mathrm{df}, \mathrm{P}<0.001$ ). During 1982 many females with purple ovaries were observed. This was shown by Ross et al. (1982) to signify imminent spawning in Euphausia pacifica. Two females with purple ovaries were kept in glass jars at $8^{\circ} \mathrm{C}$; both spawned within $2 \mathrm{~h}$ of capture. One female measured $9.3 \mathrm{~mm}$ carapace length and laid 545 eggs, the other measured $8.5 \mathrm{~mm}$ and laid 739 eggs. Stage 4 and purple ovaries contained large yolky ova and the spent ovaries contained mainly small (Stage 1 and 2 ova) but were distinguishable from less mature ovaries by their smaller size and disorganized state.

\section{Eggs in the plankton}

Newly laid Meganyctiphanes norvegica eggs were often abundant in the surface plankton in the swarming area (Fig. 7). The mean number of eggs found in the surface waters of the swarming area was significantly higher on swarming days when compared to non-swarming days (Mann-Whitney U test, $\mathrm{W}=2086$, $\mathrm{P}<0.0001$ ) and on both types of days when compared to the inshore non-swarming area (Mann-Whitney $\mathrm{U}$ test, $\mathrm{W}=511, \mathrm{P}<0.001)$. The eggs were so numerous that they occasionally were the dominant single item in the plankton sampled by the $270 \mu \mathrm{m}$ mesh net. On swarming days eggs occupied $>5 \%$ of the plankton in $50 \%$ of the samples, whereas they only occupied $>5 \%$ of the plankton in $25 \%$ of the samples from nonswarming days. That the percentage of the plankton occupied by the eggs was found to differ between swarming and non-swarming days implies that the eggs are not simply a constant portion of the plankton, the volume of which changes coincident with upwelling events.

\section{DISCUSSION}

The individuals that made up the surface swarms off Brier Island and in the 2 other swarming areas were Meganyctiphanes norvegica adults of a restricted size

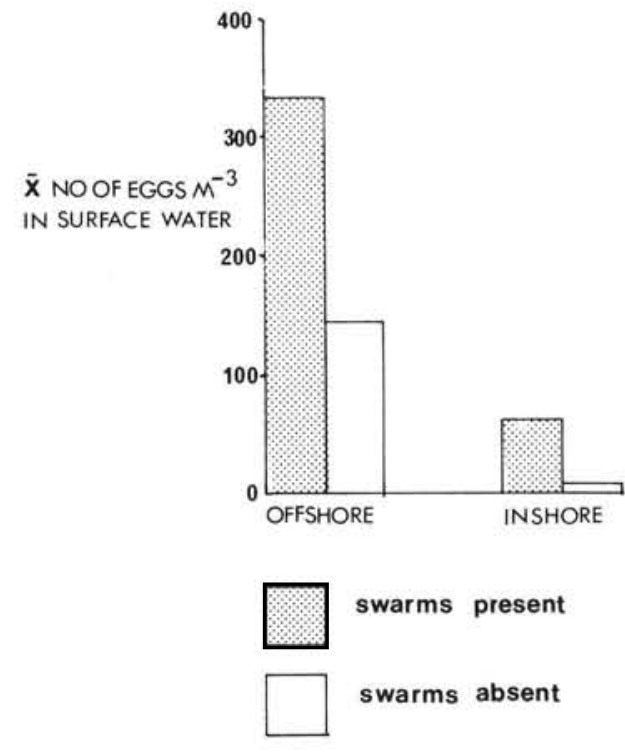

Fig. 7. Meganyctiphanes norvegica. Mean number of newly laid eggs in the surface waters of the offshore (swarming) area compared to that in the inshore (non-swarming) area on days when swarms were seen and on days when swarms were absent. Offshore refers to the area off Brier and Long Islands where swarms were most often seen; inshore is that area just to the landward where swarms were rarely seen

range. Most swarms had a skewed sex ratio and the individuals in the swarms were reproductively active. Females were in either pre- or post-spawning condition and males were in mating condition. Additionally, the presence of surface swarms was accompanied by bursts of $M$. norvegica eggs in the plankton. These facts lead to the conclusion that, whilst on the surface, swarms of $M$. norvegica are engaged in reproductive behaviour.

Hollingshead and Corey (1974) described the life history of Meganyctiphanes norvegica in Passamaquoddy Bay. Using length criteria, they divided the summer population into 2 year classes; Group I which had overwintered once and bred once and Group II which had overwintered twice and had bred twice. Other areas where the life history of $M$. norvegica has been studied during the breeding season reveal a similar pattern to that described in Passamaquoddy Bay: Berkes (1973) in the Gulf of St. Lawrence, Einarsson (1945) off Iceland, Mauchline (1960), for the Clyde sea, Wiborg (1971) and Matthews (1973) off the western coast of Norway and Lindley (1982) in the North Sea and North Atlantic. The populations sampled at depth off the Scotian Shelf in 1981 and that sampled off S.W. Nova Scotia in 1982 in the present study both fit well with the patterns of population structure of $M$. norvegica reported for other areas. The populations sampled from surface swarms, however, were marked by the absence of age classes other than the large 
Table 2. Meganyctiphanes norvegica. Size ranges reported from surface swarms (total lengths unless otherwise indicated)

\begin{tabular}{|llll|}
\hline Location & Season & Size range $(\mathrm{mm})$ & Source \\
\hline W. Scotland & - & $12-20$ & Patience (1909) \\
Gulf of Maine & Apr & 'Large specimens' & Bigelow (1926) \\
Oslofjord & Oct & $21-29$ & McDonald (1927) \\
Passamaquoddy Bay & Summer & $28-31$ & Fish \& Johnson (1937) \\
Faroes & - & $11-22$ & Einarsson (1945) \\
Monaco & Aug & $25(\overline{\mathrm{X}})$ & Fisher et al. (1953) \\
Monaco & Jan \& Feb & $15(\bar{X})$ & Fisher et al. (1953) \\
Monaco & Jan \& Feb & $25-34$ & Casanova-Soulier (1970) \\
N. Ireland & Jan & $15-36(83 \%>26)$ & Aitken (1960) \\
Isle of Man & Nov & $15-28$ & Cox (1975) \\
Brier Island & Jul-Aug & $\sim 27$ & Brown et al. (1979) \\
Brier Island & Jul-Aug & $25-35$ & Present study \\
\hline
\end{tabular}

Group II adults. The constancy of composition of the surface swarms suggests an ontogenetic migration to the surface by a particular age group.

Ten reports of the surface swarming of Meganyctiphanes norvegica are accompanied by a record of the size of the constituent animals (Table 2). Most of these reports indicate that surface swarms of $M$. norvegica consist of restricted size groups but these are not necessarily the large Group II individuals found in this study. Some surface swarms of other species of euphausiids also appear to contain limited portions of the population (Table 3). Marr (1962) maintained that swarms of Euphausia superba remained age segregated from the moment of hatching and provided many examples to support this theory. Subsequent evidence has tended to corroborate Marr's ideas for this species (Burrokovskiy, 1965; Ivanov, 1970; Makarov, 1970, 1979; Jazdzewski et al., 1978). There is some evidence that other species of euphausiids may show some form of spatial segregation as well. Einarsson (1945), Mauchline (1960), Wiborg (1971), Matthews (1973) and Kulka et al. (1982) all encountered depth segregation of the age groups in $M$. norvegica though this was not

Table 3. Size ranges of euphausiids (other than Meganyctiphanes norvegica) from surface swarms reported in the literature (total lengths unless otherwise indicated)

\begin{tabular}{|lcl|}
\hline \multicolumn{1}{|c}{ Species } & $\begin{array}{c}\text { Size range } \\
(\mathrm{mm})\end{array}$ & \multicolumn{1}{c|}{ Source } \\
\hline Euphausia superba & All sizes & Marr (1962) \\
E. pacifica & $17-19$ & Odate $(1979)$ \\
E. pacifica & $12-22$ & Terazaki (1980) \\
E. pacifica & $12-32$ & Endo (1981) \\
E. krohnii & $9-16$ & Baker $(1970)$ \\
T. inermis & $24.5(\overline{\mathrm{X}})$ & Stott $(1936)$ \\
T. raschii & $24-32$ & Zelickman (1961) \\
Thysanoessa & $11-16$ & Forsyth \& Jones \\
longicaudata & & $(1966)$ \\
Nyctiphanes capensis & Calyptopes & Thomas (1980) \\
\hline
\end{tabular}

complete and the age groups were all found in the same area. Kulka and Corey (1978) found similar depth segregation of Thysanoessa inermis in the Bay of Fundy, with the older stages being found deeper than the younger ones.

The highly skewed sex ratios observed in the surface swarms of Meganyctiphanes norvegica have their parallel in the literature both for populations at depth and on the surface. Aperiodic fluctuations in the sex ratio have been reported in most studies into the life history of this species: (Mauchline, 1960; Wiborg, 1971; Berkes, 1973; Hollingshead and Corey, 1974). Other species of euphausiids also show these fluctuations in sex ratio (Thysanoessa inermis: LaCroix, 1961; Berkes, 1973; Jorgensen and Matthews, 1975; Kulka, 1976; Euphausia superba: Marr, 1962; E. pacifica: Ponomareva, 1966; Brinton, 1976). Surface swarms of euphausiids can have sex ratios which range from completely male to completely female (Table 4). Fluctuations in sex ratios observed in most euphausiid populations and surface swarms that have been intensively studied can be explained in several ways. Brinton (1976) suggests that apparent female dominance of catches of $E$. pacifica could be caused by mistaken identification of males, increasing size-related mortality among males and net avoidance by males. The most common explanation of skewed sex ratios is that of differential sex-related mortality (Mauchline, 1960). This argument is tautological since the differential mortality is inferred only from the changes in the sex ratio for which an explanation is sought. Additionally, the apparently random fluctuations in the sex ratio of most populations studied do not follow a pattern that might be expected if the changes were due to regular losses of certain segments of the population. Perhaps the simplest explanation and the one with the most observational evidence is that some species of euphausiids at certain times of the year may exhibit segregation of the sexes. This separation may be either 
Table 4. Reported sex ratios of surface swarms of euphausiids

\begin{tabular}{lll|}
\hline \multicolumn{1}{|c}{ Species } & \% female & Source \\
\hline Meganyctiphanes norvegica & 56 & Aitken (1960) \\
Meganyctiphanes norvegica & 89 & Casanova-Soulier (1970) \\
Meganyctiphanes norvegica & 50 & Cox (1975) \\
Meganyctiphanes norvegica & 17 & Brown et al. (1979) \\
Meganyctiphanes norvegica & $6-100$ & Present study \\
Euphausia pacifica & 40 & Terazaki (1980) \\
Euphausia pacifica & 50 & Endo (1981) \\
Thysanoessa longicaudata & 63 & Forsyth and Jones (1966) \\
Euphausia superba & $29-98$ & Marr (1962) \\
Euphausia superba & $0-75$ & Nemoto and Nasu (1975) \\
Euphausia superba & $0-100$ & Nemoto et al. (1981) \\
Thysanoessa raschii & 63 & Zelickman (1961) \\
\hline
\end{tabular}

horizontal (as in this study) or vertical (Wiborg, 1971), rather than temporal as other workers have suggested. The strategy of sexual segregation in a reproductive population has no obvious advantages, however, sexually segregated swarms are not uncommon reproductive entities among the arthropods (cladocera: Ratzlaff, 1974; Young, 1978 and Byron et al., 1983; copepods: Ueda, 1983) and anchovy schools with highly skewed sex ratios have been reported (Klingbeil, 1980). Sex related size differences and associated differential swimming speeds may be a passive mechanism for sexual segregation in schooling animals.

If the population consists of small patches (or swarms) each with a unique sex ratio, then sampling by either conventional (integrating) techniques or by point samples (as used in this study) will generally produce results that do not represent the sex ratio of the population. A net tow could sample a single swarm, many swarms or no swarms at all. In contrast, dip nets sample known surface swarms, but the population mean sex ratio can only be determined by numerous samples from separate swarms. If a population mean sex ratio is wanted then repetitive sampling is necessary with either towed nets or dip nets in surface swarms. If, however, the intimate fine-scale structure of either the population or surface swarms is being investigated, then point samples are essential.

The ovarian condition of the females and the presence of eggs in the plankton indicates that a certain proportion of the females in the swarms are spawning at the surface. It also seems likely that females are being fertilized whilst at the surface. Copulation has not been observed in euphausiids and the small numbers of males with extruded spermatophores and small number of females with newly attached spermatophores indicates that the transfer of sperm and the loss of the empty spermatophores may be a rapid process. Einarsson (1945) commented on the absence of attached spermatophores on female Meganyctiphanes norvegica which is unusual because they are usually found on fertilized females of other species. Costanzo and Guglielmo (1979) suggested that this absence is because of the rapid discharge of the spermatophores either during, or immediately following, copulation. The breeding season of $M$. norvegica off Eastern Canada is from June to Sept (Berkes, 1973; Hollingshead and Corey, 1974) and this corresponds well to the swarming season (Brown et al., 1979) further suggesting a link between the 2 processes.

There are many allusions to the reproductive nature of surface swarms but little evidence has been presented to support this contention. Casanova-Soulier (1970) found mainly gravid females with sperm masses in surface swarms of Meganyctiphanes norvegica off Monaco; Endo (1981) indicated that both spermatophore transfer and spawning were taking place in surface swarms of Euphausia pacifica; Keats (1981) found euphausiid eggs in the plankton taken from a swarm of Thysanoessa raschii. Lomakina (1968) alleged that most species of euphausiids lay their eggs in the surface layers; Ponomareva (1966) noted that euphausiid concentrations 'have not been observed in the Pacific for any other purpose ... than breeding', and Zelickman (1961) reported surface swarming by $T$. inermis and $T$. raschii in the last phase of gonad ripening. Hjort and Rudd (1929) wrote: 'Our researches off More have convinced us that schizopods only swarm during breeding time.'

Non-reproductive surface swarms of euphausiids have been reported. Einarsson (1945) encountered swarms of immature Meganyctiphanes norvegica; Marr (1962) found that swarms of Euphausia superba were not confined to the spawners, and Thomas (1980) reported a swarm of Nyctiphanes capensis larvae. The swarm of $M$. norvegica reported by Brown et al. (1979) for the Brier Island area was described as consisting of 
immature animals but the carapace length data that they present indicates that the swarm was, in fact, composed of adults.

Surface swarming as a reproductive strategy has several possible advantages. The sea surface acts as a barrier where a dispersed pelagic population can be concentrated. Aggregation of the reproductive adults at the surface during daylight would bring about a separation of these animals from the non-reproductive portion of the population which remains deep during the day, thus facilitating mate location. The advantages of laying eggs at the surface has been stressed by Marr (1962) who proposed that the eggs develop as they sink. Marschall (1983) described Meganyctiphanes norvegica eggs taking $60 \mathrm{~h}$ to reach a free swimming stage at $10^{\circ} \mathrm{C}$, and at this temperature he calculated that they would have reached 190 to $290 \mathrm{~m}$ in still water before hatching. The maximum depth in the Bay of Fundy is $223 \mathrm{~m}$ which indicates that eggs laid at the surface off Brier Island may well have developed into the free swimming first nauplius before reaching the benthos.

Surface swarming by euphausiids is unlikely to have a single triggering mechanism amongst all the species in which it is known to occur. Certain species such as Euphausia superba swarm regularly and this behaviour is encountered in all life history stages. Other species such as Meganyctiphanes norvegica and E. pacifica are encountered at the surface more rarely and often appear to be fulfilling a specific, reproductive function. Still further species such as Nyctiphanes australis appear to form reproductive swarms, but, because the eggs are retained by the females following spawning, the exact stimulus for the formation of these swarms is more obscure. The search for general rules which govern the ultimate and proximate causes of this behaviour in euphausiids must await further specific and comparative studies.

Acknowledgements. I thank Dr. R. K. O'Dor for helpful criticism of several drafts of this manuscript and P. Pepin for the swarm sample from North Sydney. This project was funded by Fisheries and Oceans (Canada) subventions to Dr. R. K. O'Dor, by NSERC (Canada) grants to Dr. C. M. Boyd, by a Dalhousie University Graduate Fellowship and by an award from the Lerner-Gray Fund for Marine Research of the American Museum of Natural History.

\section{LITERATURE CITED}

Aitken, J. J. (1960). Swarming in Meganyctiphanes norvegica (M. Sars) in Strangford Lough, Co. Down. Ir. Nat. J. 13: 140-142

Baker, A. de C. (1970). The vertical distribution of euphausiids near Fuerteventura, Canary Islands. J. mar. biol. Ass. U.K. 50: 301-342
Berkes, F. (1973). Production and comparative ecology of euphausiids in the Gulf of St. Lawrence. Ph. D. Dissertation, McGill University

Bigelow, H. B. (1926). Plankton of the offshore waters of the Gulf of Maine. Bull. Bur. Fish., Wash. 40 (2): 1-509

Brinton, E. (1976). Population biology of Euphausia pacifica off Southern California. Fish. Bull. NOAA U.S. 74: 733-762

Brown, R. G. B., Barker, S. P., Gaskin, D. E. (1979). Daytime surface swarming by Meganyctiphanes norvegica off Brier Island, Bay of Fundy. Can. J. Zool. 57 (12): 2285-2291

Burukovskiy, R. N. (1965). Certain problems of the biology of the Antarctic krill Euphausia superba from the south west region of the Scotian Sea. In: Burukovskiy, R. N. (ed.) Soviet fishery research on Antarctic krill. Atlantic NIRO, Kalingrad, USSR, p. 37-53

Byron, E. R., Whitman, P. T., Goldman, C. R. (1983). Observations of copepod swarms in Lake Tahoe. Limnol. Oceanogr. 28 (2): $378-383$

Casanova-Soulier, B. (1970). Les rassemblements d'euphausiaces en Medeterranee. Rapp. P.-v. Réun. Commn int. Explor. scient. Mer Méditerr. 20: 435-437

Constanzo, G., Guglielmo, L. (1979). On the transfer of spermatophores in preserved specimens of Meganyctiphanes norvegica (M. Sars) (crustacea; euphausiacea). Atti Soc. pelorit. Sci. fis. mat. nat. XXV (1): 103-109

Cox, S. J. (1975). Shore stranding of Meganyctiphanes norvegica (M. Sars). Estuar. coast. mar. Sci. 3: 483-484

Einarsson, H. (1945). Euphausiacea. 1. North Atlantic species. Dana Rep. 27: 1-185

Endo, Y. (1981). Ecological studies on the euphausiids occurring in Sanriku waters with special references to their life history and aggregated distribution. $\mathrm{Ph}$. $\mathrm{D}$. thesis, Tohuko Univ., Sendai

Fish, C. J., Johnson, M. W. (1937). The biology of the zooplankton population in the Bay of Fundy and Gulf of Maine with special reference to production and distribution. J. Biol. Bd Can. 3: 189-322

Fisher, L. R., Kon, S. K., Thompson, S. Y. (1953). Vitamin A and carotenoids in some Mediterranean crustacea with a note on the swarn 3 of Meganyctiphanes. Bull. Inst. Oceanogr. Monaco 1U21: 1-19

Forsyth, D. C. T., Jones, L. T. (1966). Swarming of Thysanoessa longicaudata (Kroyer) (crustacea, euphausiacea) in the Shetland Isles. Nature, Lond. 212: 1467-1468

Hamner, W. M., Hamner, P. P., Strand, S. W., Gilmer, R. W. (1983). Behaviour of Antarctic krill, Euphausia superba: chemoreception, feeding, schooling and molting. Science, N.Y. 220: $433-435$

Hjort, J., Rudd, J. T. (1929). Whaling and fishing in the North Atlantic. Rapp. P.-v. Reun. Cons. int. Explor. Mer 56: $5-123$

Hollingshead, K. W., Corey, S. (1974). Aspects of the life history of Meganyctiphanes norvegica (M. Sars) crustacea (euphausiacea) in Passamaquoddy Bay. Can. J. Zool. 52: 495-505

Ivanov, B. (1970). On the Biology of the Antarctic krill. (Euphausia superba Dana). Mar. Biol. 7: 340-351

Jazdzewski, K., Dzik, J., Porebski, J., Rakusa-Suscwski, S., Witek, Z., Wolnomiejski, N. (1978). Biological and populational studies on krill near the South Shetland Isles, Scotia Sea and South Georgia in Summer 1976. Polskie Arch. Hydrobiol. 25 (3): 607-631

Jorgensen, C., Matthews, J. B. L. (1975). Ecological studies on the deep water pelagic community of Korsfjorden, Western Norway. Population dynamics of six species of euphausiids in 1968 and 1969. Sarsia 59: 67-84 
Keats, D. (1981). Humpbacks feeding in Conception Bay. Osprey 12: 65

Klingbeil, R. A. (1980). Sex ratios of anchovy Engraulis mordax off Southern California. Calif. Fish Game 64: 200-209

Komaki, Y. (1967). On the surface swarming of euphausiid crustaceans. Pacif. Sci. 21: 433-448

Kulka, D. W. (1976). The life history of Thysanoessa inermis (Kroyer) and the community structure of euphausiids in the Bay of Fundy. M. Sc, thesis, University of Guelph

Kulka, D. W., Corey, S. (1978). The life history of Thysanoessa inermis in the Bay of Fundy. Can. J. Zool. 56: 492-506

Kulka, D. W., Corey, S., Iles, T. D. (1982). The community structure and biomass of euphausiids in the Bay of Fundy. Can. J. Fish. aquat. Sci. 39: 326-334

Lacroix, G. (1961). Les migrations verticales journalieres des euphausides a l'entree de la Bai de Chaleurs. Nature, Can. LXXXVIII (11): 257-316

Lindley, J. A. (1982). Population dynamics and production of euphausiids. III. Meganyctiphanes norvegica and $\mathrm{NyC}$ tiphanes couchii in the North Atlantic Ocean and the North Sea. Mar. Biol. 66: 37-46

Lomakina, N. B. (1968). Euphausiids of the world ocean. Studies of the fauna of the USSR. Zoological Institute of the Academy of Science, USSR

Macdonald, R. (1927). Food and habits of Meganyctiphanes norvegica. J. mar. biol. Ass. U.K. 14: 785-794

Makarov, R. R. (1970). Separate existence of various age groups of Antarctic krill. Inf. Bull. Sov. Ant. Exped. 77: $547-550$

Makarov, R. R. (1979). Size composition and conditions of existence of Euphausia superba Dana (Crustacea: euphausiacea) in the eastern part of the Pacific sector of the Southern Ocean. Oceanology 19 (5): 582-585

Marr, J. W. S. (1962). The natural history and geography of the Antarctic krill (Euphausia superba). 'Discovery' Rep. 32: 33-464

Marschall, H. P. (1983). Sinking speed and size of euphausiid eggs. Meeresforsch. 30: 1-9

Matthews, J. B. L. (1973). Ecological studies on the deep water pelagic community of Korsfjorden, Western norway. Population dynamics of Meganyctiphanes norvegica (crustacea, euphausiacea) in 1968 and 1969. Sarsia 54: 75-90

Mauchline, J. (1960). The Biology of the euphausiid crustacean Meganyctiphanes norvegica (M. Sars). Proc. R. Soc. Edinb. B. (Biol) 67: 141-179

Mauchline, J. (1980). The biology of mysids and euphausiids. Adv. mar. Biol. 18: 1-681
Mauchline, J., Fisher, L. R. (1969). The biology of euphausiids. Adv. mar. Biol. 7 : 1-454

Nemoto, T., Nasu, K. (1975). Present status of exploitation and biology of krill in the Antarctic. In: Oceanology International 75: into deeper waters. BPS exhibitions, London, p. $353-360$

Nemoto, T., Doi, T., Nasu, K. (1981). Biological characteristics of krill caught in the Southern Ocean. In: Biomass, Vol II, Selected contributions to the Woods Hole Conference on living resources of the Southern Ocean, 1976. SCAR, Cambridge, p. $47-64$

Odate, K. (1979). An euphausiid crustacean exploited along the Sanriku and Joban coast. Bull. Tohoku reg. Fish. Res. Lab. 40: $15-25$

Patience, A. (1909). Transactions of the Bureshire, Vol. III. Natural History Society, Edingburgh

Ponomareva, L. A. (1966). The euphausiids of the North Pacific, their distribution and ecology. Dokl. Akad. Nauk. SSSR, 1-142. Israel programme for scientific translation

Ratzlaff, W. (1974). Swarming in Moina affinis. Limnol. Oceanogr. 19: 993-995

Ross, R. M., Kendra, L. D., English, T. S. (1982). Reproductive cycle and fecundity of Euphausia pacifica in Puget Sound, Washington. Limnol. Oceanogr. 27 (2): 304-314

Stott, F. C. (1936). The marine foods of birds in an inland fjord region west of Spitzbergen. Part 1. Plankton and shore benthos. J. Anim. Ecol. 5: 356-369

Terazaki, M. (1980). Surface swarms of a euphausiid Euphausia pacifica in Otsuchi Bay, Northern Japan. Bull. Plankt. Soc. Japan 27 (1): 19-25

Thomas, R. M. (1980). A note on swarms of Nyctiphanes capensis (Hansen) larvae off South West Africa. Fish. Bull. S. Afr. 13: 21-23

Ueda, H., Kuwahara, A., Tanaka, M., Azeta, M. (1983). Underwater observations on copepod swarms in temperate and subtropical waters. Mar. Ecol. Prog. Ser. 11: 165-171

Wiborg, K. F. (1971). Investigations on euphausiids in some fjords on the west coast of Norway 1966-1969. FiskDir. Skr. (Ser. Hav. Unders.) 16: 10-35

Young, J. P. W. (1978). Sexual swarms in Daphnia magna: a cyclic parthenenogen. Freshwat. Biol. 8: 279-281

Zelickman, E. A. (1961). The behaviour patterns of the Barents Sea euphausiacea and possible causes of seasonal vertical migrations. Int. Revue ges. Hydrobiol. 46 (2): 276-281 